Journal of Physical Science, Vol. 29(Supp. 2), 257-264, 2018

\title{
Synthesis of Zinc Oxide Whiskers with Hydrothermal Method for Composite Absorbent Material of Microwave of $\mathrm{ZnOw} / \mathrm{MWCNT} / \mathrm{Epoxy}$
}

\author{
Mohammad Wahyu Ristiawan, ${ }^{1 *}$ Priyono, ${ }^{1}$ Agus Subagio, ${ }^{1}$ Arifin Muhammad Abdul \\ Kholil $^{1}$ and Andhika Ajiesastra ${ }^{2}$ \\ ${ }^{1}$ Department of Physics, Faculty of Science and Mathematics, Diponegoro University, \\ UNDIP Semarang, 50275 Indonesia \\ ${ }^{2}$ Research and Development Center, Ministry of Defence, Republic of Indonesia, \\ PUSLITBANG IPTEKHAN Jakarta, 12450 Indonesia
}

*Corresponding author: ri.wahyu@st.fisika.undip.ac.id

Published online: 30 July 2018

To cite this article: Ristiawan, M. W. et al. (2018). Synthesis of zinc oxide whiskers with hydrothermal method for composite absorbent material of microwave of ZnOw/MWCNT/ epoxy. J. Phys. Sci., 29(Supp. 2), 257-264, https://doi.org/10.21315/jps2018.29.s2.20

To link to this article: https://doi.org/10.21315/jps2018.29.s2.20

\begin{abstract}
The MWCNT/ZnOw/epoxy composites have great potential as microwave absorbing material. The synthesis of $\mathrm{ZnO}$ whiskers ( $\mathrm{ZnOw}$ ) was carried out using precursors $\mathrm{ZnSO}_{4}$ and $\mathrm{Na}_{2} \mathrm{CO}_{3}$ via hydrothermal method with temperatures of $120^{\circ} \mathrm{C}, 160^{\circ} \mathrm{C}, 200^{\circ} \mathrm{C}$, and $240^{\circ} \mathrm{C}$. X-ray diffraction (XRD) and scanning electron microscope (SEM) were applied to find out the morphology and structure of $\mathrm{ZnOw}$ powder. The best results of the $X R D$ and SEM-EDX at hydrothermal temperature of $160^{\circ} \mathrm{C}$ showed the best crystallinity of $\mathrm{ZnO}$ compound, that is at $2 \theta$ values of $31.7^{\circ}, 32.2^{\circ}, 34.3^{\circ}, 36.1^{\circ}, 37.9^{\circ}, 56.5^{\circ}, 62.8^{\circ}$, $67.8^{\circ}, 76.8^{\circ}$ and $89.5^{\circ}$ with a Miller index of 111, 100, 002, 101, 102, 110, 103, 112, 202 and 203, respectively. At $160^{\circ} \mathrm{C}, \mathrm{ZnO}$ whiskers had a size of $97.7 \mathrm{~nm}$, with a purity level of $72.6 \%$. By adding 4\% MWCNT, the result of synthesis via spray pyrolysis method (purity 90\%) and 4\% of epoxy, the ZnOw synthesised by hydrothermal method formed MWCNT/ ZnOw/epoxy composites. To determine the composite's microwave absorption capability, a vector network analyser was administered at hydrothermal temperatures of $160^{\circ} \mathrm{C}$ and $200^{\circ} \mathrm{C}$. The $\mathrm{MWCNT/ZnOw/epoxy} \mathrm{composites} \mathrm{had} \mathrm{a} \mathrm{reflection} \mathrm{loss} \mathrm{of}-11.9 \mathrm{~dB}$. This value exceeds the standard for microwave absorbing material which is $-11.9 \mathrm{~dB}$. Therefore, the composite has great potential as a microwave absorbing material.
\end{abstract}

Keywords: Zinc oxide whiskers, hydrothermal, MWCNT, composites, ZnOw

(C) Penerbit Universiti Sains Malaysia, 2018. This work is licensed under the terms of the Creative Commons Attribution (CC BY) (http://creativecommons.org/licenses/by/4.0/). 


\section{INTRODUCTION}

Anti-radar technology has been developed involving two primary methods. The first method is radar absorbing structure (RAS) which involves manipulating the object geometry shape. ${ }^{1}$ The second method uses a radar absorbing material called radar-absorbing material (RAM), which is done by modifying the object-material. ${ }^{1}$ To improve the efficiency of RAM, numerous studies have been conducted to obtain optimal materials for absorbing microwaves. ${ }^{1}$

Zinc oxide is a derivative compound of zinc elements that have good physical characteristics. Hence, it is often applied in various technology products such as thin layer technology, supercapacitors, anti-radar technology and electronic devices. ${ }^{2}$ One form of zinc oxide that has a unique morphology is $\mathrm{ZnO}$ whiskers $(\mathrm{ZnOw}){ }^{3}$ $\mathrm{ZnOw}$ has a resistivity value of $0.62-0.65 \times 103 \Omega \mathrm{m}$. Therefore, it is classified as a semiconductor material. This is one of the characteristics of microwave absorbing materials. $^{4}$

The synthesis of $\mathrm{ZnOw}$ using the hydrothermal method has several precursors that can be used. For example, synthesis of $\mathrm{ZnO}$ whiskers used precursors $\mathrm{Zn}(\mathrm{OH})$ referring to Liu et al., used precursors $\mathrm{Zn}\left(\mathrm{NO}_{3}\right)_{2}$ referring to Shen et al., and used precursors $\mathrm{ZnSO}_{4}$ (Wen et al.). ${ }^{5-7}$ The higher the temperature used, the lower the hydroxyl group (OH-) gets, indicating a better crystal form of $\mathrm{ZnOw}$. However, to support this study, the authors use a variation of hydrothermal temperatures referring to Wang et al. ${ }^{8}$

To improve the quality, $\mathrm{ZnO}$ whiskers' microwave absorption must be formed into composite MWCNT/ZnOw/epoxy. ${ }^{9}$ For example, the composites of $\mathrm{ZnO} /$ MWCNT/epoxy have the reflection loss value of $23.00 \mathrm{~dB}$ with a small density of $0.14 \mathrm{~g} \mathrm{~cm}^{-3} .{ }^{10}$ Therefore, it can be lighter when applied as a RAM material. In this study, the authors use composite MWCNT/ZnOw/epoxy with a certain composition to obtain a material that has characteristics allowing for maximal absorption of the microwave. Here in this paper, we demonstrate the hydrothermal method to synthesise $\mathrm{ZnO}$ nanostructures. We also prepare the composites of $\mathrm{ZnO} /$ MWCNT/epoxy to increase the microwave absorbance. 


\section{EXPERIMENTAL}

\subsection{Materials}

Zinc sulfate heptahydrate $\left(\mathrm{ZnSO}_{4}\right)$, sodium carbonate $\left(\mathrm{Na}_{2} \mathrm{CO}_{3}\right) 0.25 \mathrm{~mol} \mathrm{l}^{-1}$ and a solvent of distilled water $\left(\mathrm{H}_{2} \mathrm{O}\right)$ are prepared. ${ }^{7}$ The synthesis of MWCNT with purity $92 \%$ uses ferrocene and benzene. To form the $\mathrm{ZnOw} / \mathrm{MWCNT} / \mathrm{epoxy}$, a poxy resin matrix is used. All chemicals are analytical grade reagent from Merck KGaA, Germany.

\subsection{Synthesis of $\mathrm{ZnO}$ Powder Whiskers}

Synthesis of $\mathrm{ZnO}$ whisker powder uses precursor materials zinc sulfate heptahydrate $\left(\mathrm{ZnSO}_{4}\right) \quad 0.4 \mathrm{~mol} \mathrm{l^{-1 }}$ and sodium carbonate $\left(\mathrm{Na}_{2} \mathrm{SO}_{4}\right) 0.25 \mathrm{~mol} \mathrm{l}^{-1}$ and a solvent of distilled water $\left(\mathrm{H}_{2} \mathrm{O}\right) .^{7}$ The synthesis maintains hydrothermal temperature $160^{\circ} \mathrm{C}$ after about $6 \mathrm{~h}$ using Teflon-lined stainless stell autoclave. Then it is cleaned by distilled water $\left(\mathrm{H}_{2} \mathrm{O}\right)$ and it is also dried at $60^{\circ} \mathrm{C}$ for about $6 \mathrm{~h} .{ }^{10}$

\subsection{Forming ZnOw/MWCNT/Epoxy Composites}

ZnOw/MWCNT/epoxy composite consists of three main materials: 4\% MWCNT that had been synthesised by spray pyrolysis method, the synthesis result of $90 \%$ $\mathrm{ZnOw}$ using the hydrothermal method, and $4 \%$ epoxies as matrix. ${ }^{11}$ Composite MWCNT/ZnOw/epoxy is printed into $2.3 \mathrm{~cm} \times 1.1 \mathrm{~cm}$ in width and thickness of $2 \mathrm{~mm}$.

\subsection{Characterisation}

To find out the morphology and structure of $\mathrm{ZnO}$ whisker powder, $\mathrm{X}$-ray diffraction (XRD) (Phillip analytical X-Ray B.V) with CuKa radiation $(\lambda=1.5418 \AA$ ) at $40 \mathrm{KV}$ and scanning electron microscopy (SEM JEOL JSM-6390A). To find out the composite capability of MWCNT/ZnOw/Epoxy in absorbing microwaves, a vector network analyser is used.

\section{RESULTS AND DISCUSSION}

\subsection{Morphological Analysis of $\mathrm{ZnOw}$}

To obtain the morphology and structure of $\mathrm{ZnO}$ whisker powder, XRD and SEM are used. The XRD is aimed to analyse qualitatively the $\mathrm{ZnO}$ whisker particles 
that use the hydrothermal process of the compound $\mathrm{ZnCO}_{3} .{ }^{12}$ To form the $\mathrm{ZnO}$ whiskers, $\mathrm{ZnSO}_{4}$ and $\mathrm{Na}_{2} \mathrm{CO}_{3}$ are applied as the precursor in reaction to a test:

$$
\begin{aligned}
& \mathrm{ZnSO}_{4}+\mathrm{Na}_{2} \mathrm{CO}_{3}+7 \mathrm{H}_{2} \mathrm{O}=\mathrm{Zn}\left(\mathrm{CO}_{3}\right)+\mathrm{Na}_{2} \mathrm{SO}_{4}+\mathrm{H}_{2} \mathrm{O} \\
& \mathrm{Zn}\left(\mathrm{CO}_{3}\right)=\mathrm{ZnO}+2 \mathrm{CO}_{2}
\end{aligned}
$$

The XRD uses five samples. The samples consist of $\mathrm{ZnO}$ confronted with hydrothermal processes at temperature of $\mathrm{T}=160^{\circ} \mathrm{C}$ about $6 \mathrm{~h}$ and $\mathrm{ZnCO}_{3}$ before hydrothermal. The results of the XRD can be seen in Figure 1.

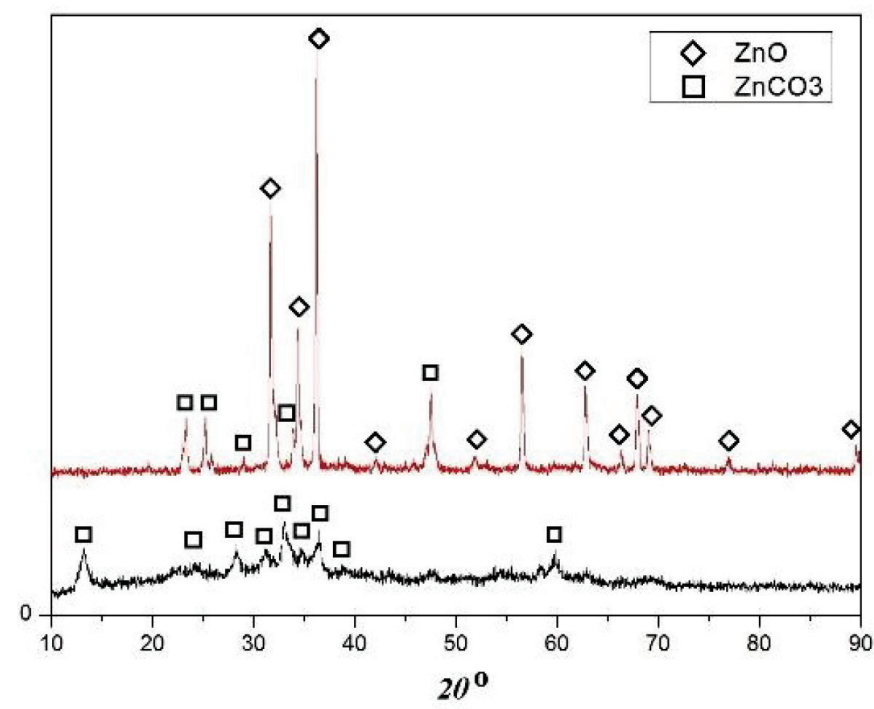

Figure 1: $\mathrm{XRD}$ analysis of $\mathrm{ZnO}$ and $\mathrm{ZnCO}_{3}$ before the hydrothermal processing, where the compound that has been formed is $\mathrm{ZnCO}_{3}$.

The results of XRD show some peaks corresponding to the values of the $2 \theta$ compound of $\mathrm{ZnCO}_{3}$ in JCPDS database (PDF No.19-1458). The peak hydrothermal temperature of $160^{\circ} \mathrm{C}$ is indicated by the crystallinity of $\mathrm{ZnCO}_{3}$ compound at $2 \theta$ values of $23.3^{\circ}, 25.2^{\circ}$ and $28.0^{\circ}$ in directions to 111,400 and 200 . These results at the hydrothermal temperature of the $160^{\circ} \mathrm{C}$ show the peak corresponding to the values between at least the values of $2 \theta \mathrm{ZnCO}_{3}$ at JCPDS database (PDF No.191458 ) and the lowest intensity that shows the low crystallinity value of $\mathrm{ZnCO}_{3}$. Besides the research by Wen et al. with hydrothermal temperature of $160^{\circ} \mathrm{C}$, the results of crystallinity in this study are better due to the peak corresponding value of $\mathrm{Zn}_{5}\left(\mathrm{CO}_{3}\right)_{2}(\mathrm{OH})_{6}$ in JCPDS database (PDF No.19-1458) which is less and has lower intensity. ${ }^{7}$ 
The crystallinity level of $\mathrm{ZnO}$ is determined by analysing the peak corresponding to the value of $2 \theta \mathrm{ZnO}$ compound in JCPDS database (PDF No.36-1451). ${ }^{7}$ At hydrothermal temperature of $160^{\circ} \mathrm{C}$, the peak indicates the crystallinity of the $\mathrm{ZnO}$ compound $2 \theta$ values of $31.7^{\circ}, 32.2^{\circ}, 34.3^{\circ}, 36.1^{\circ}, 37.9^{\circ}, 56.5^{\circ}, 62.8^{\circ}, 67.8^{\circ}, 76.8^{\circ}$ and $89.5^{\circ}$ in directions towards $111,100,002,101,102,110,103,112,202$ and 203. These results show that the peak correspondence to the value of $2 \theta \mathrm{ZnO}$ compound in JCPDS database is the highest intensity, which means the crystallinity value of $\mathrm{ZnO}$ compound is high. ${ }^{7}$ Proper hydrothermal temperatures can affect the level of crystallinity of $\mathrm{ZnO}^{7}$ The results of crystallinity in this study are better due to the peak correspondence to the value of $2 \theta \mathrm{ZnO}$ compound in JCPDS database (PDF No.19-1458) which is greater and has higher intensity.

The SEM shows that $\mathrm{ZnO}$ whiskers/ $\mathrm{ZnO}$ root has been formed at hydrothermal temperature of $160^{\circ} \mathrm{C}$ for $6 \mathrm{~h}$. At $160^{\circ} \mathrm{C}$, the size of $\mathrm{ZnO}$ becomes $97.7 \mathrm{~nm}$ in length. The nanomaterials are less than $100 \mathrm{~nm}$ in length. ${ }^{13}$ At $160^{\circ} \mathrm{C}, \mathrm{ZnO}$ materials form nanomaterials. SEM is used to analyse the size and types of $\mathrm{ZnO}$ and MWCNT formed. ${ }^{14}$ The SEM results can be seen in Figure 2.
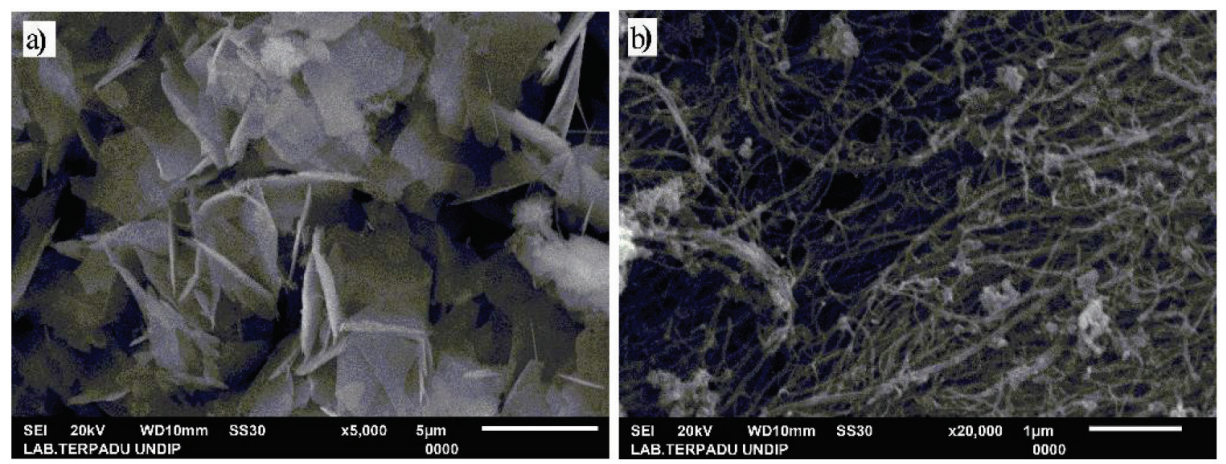

Figure 2: Test results of $\mathrm{ZnO}$ and MWCNT magnification 5000X with a) $\mathrm{ZnO}$ hydrothermal $160^{\circ} \mathrm{C}$, and b) MWCNT.

SEM results show that the carbon nanotubes form well. The carbon nanotubes are synthesised using a spray pyrolysis process that has been formed based on SEM results that are part of MWCNT. SWCNT takes the form of rolled cylindrical sheets of graphite that are $0.2-5 \mu \mathrm{m}$ in length and 1-2 nm in diameter. ${ }^{15}$ An SWCNT consists of two parts: the side wall of the cylinder, and the peaks of the cylinder. ${ }^{15}$ The form of MWCNT is the same as the form of SWCNT which consists of many rolls of $2-25 \mathrm{~nm}$ in diameter. ${ }^{15}$ 


\subsection{Absorption Analysis of $\mathrm{ZnOw} / \mathrm{MWCNT} / \mathrm{Epoxy}$ Composite Waves}

To study the composite capability of $\mathrm{ZnOw} / \mathrm{MWCNT} / \mathrm{epoxy}$ in absorbing microwaves, vector network analyser (VNA) is utilised. ${ }^{25}$ The VNA test is used to find out the value of reflection loss, transmission loss and microwave absorption through compositing. Reflection loss is the main parameter to find out the antiradar capability of composite MWCNT/ZnOw/epoxy. The reflection loss values can be seen in Figure 3.

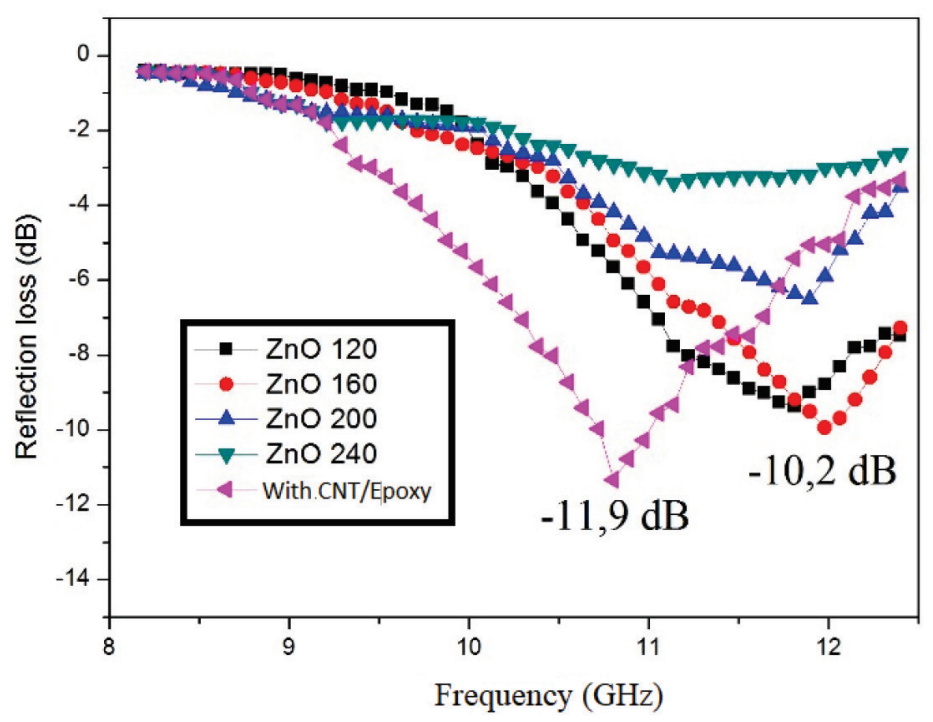

Figure 3: Reflection loss values of composite MWCNT/ZnOw/epoxy.

At hydrothermal temperature of $120^{\circ} \mathrm{C}$, the reflection loss value is $-2.1 \mathrm{~dB}$. At $160^{\circ} \mathrm{C}$, the value is $-10.2 \mathrm{~dB}$, while at $200^{\circ} \mathrm{C}$, the value is $-6.8 \mathrm{~dB}$. At $240^{\circ} \mathrm{C}$, the reflection loss is $-8.9 \mathrm{~dB}$. The reflection loss value of $\mathrm{ZnOw} / \mathrm{MWCNT} /$ epoxies is $-11.9 \mathrm{~dB}$. Hydrothermal temperature of $160^{\circ} \mathrm{C}$ has the highest reflection loss value; EDXtests of the results at hydrothermal temperature $160^{\circ} \mathrm{C}$ shows the highest content of $\mathrm{C}$ atoms, which is as high as $63.3 \%$. According to Liu et al., carbon is a dielectric material that has the capacity for polarisation and absorption of electromagnetic waves that converts them into heat energy. ${ }^{7,16}$ When the electromagnetic waves hit the material, the polarisation occurs due to field of electric wave that creates an electric current, converting into heat through the Joule effect. ${ }^{17} \mathrm{ZnO}$ is a semiconductor material that has the ability to absorb electromagnetic waves by converting the energy of electromagnetic waves into heat energy. ${ }^{17}$ 


\section{CONCLUSION}

The results of the morphological analysis using XRD and SEM-EDX show that the material $\mathrm{ZnO}$ whiskers form well at hydrothermal temperature of $160^{\circ} \mathrm{C}$. The results also show that the MWCNT material formed well. The test results of the anti-radar capability of composite MWCNT/ZnOw/epoxy that use VNA at a hydrothermal temperature of $160^{\circ} \mathrm{C}$ and MWCNT show that reflection loss values of composite MWCNT/ZnOw/epoxy are $-10.2 \mathrm{~dB}$ and $-11.9 \mathrm{~dB}$, respectively.

\section{ACKNOWLEDGEMENTS}

The authors thank all parties which have been supporting this research work. The authors also would like to thank Diponegoro University and The Ministry of Research, Technology and Higher Education, Indonesia for financial support. They are also indebted to Mr. Chasbullah Hindratmo for his valuable assistance in Laboratory Nanotechnology, Diponegoro University.

\section{REFERENCES}

1. Yin, L. et al. (2014). Electromagnetic properties of Si-C-N based ceramics and composites. Int. Mater, 326-355.

2. Buruah, S. \& Duta, J. (2009). Hydrothermal growth of $\mathrm{ZnO}$ nanostructures. Sc. Technol., 10, 13-31.

3. Day, Y. et al. (2002). Synthesis and optical properties of tetrapod-like zinc oxide nanorods. Chem. Phys. Lett., 358, 83-86.

4. Kato, H. et al. (2002). Growth and characterization of ZnO. J. Cryst. Growth, 538, 237-239.

5. Liu, C. Y. et al. (2006). Preparation of $\mathrm{ZnO}$ cluster and rod like whiskers through hydrothermal methods. Mater. Lett., 60, 1394-1398.

6. Shen, L. (2007). Organic molecule-assisted hydrothermal self-assembly of size- controlled tubular ZnO Nanostructures. J. Phys. Chem. C, 111: 72807287.

7. Wen, S. T. et al. (2010). Synthesis of $\mathrm{ZnO}$ whiskers via hydrothermal decomposition route. Trans. Nonf. Met. Soc. Chin., 20, 1049-1052.

8. Wang, Z. L. et al. (2006). Zinc oxide nanostructures: Growth, properties, and applications. J. Phys. Condens. Matt., 16, 529-858.

9. Liu, G. et al. (2012). Enhanced electromagnetic absorption properties of carbon nanotubes and zinc oxide whiskers microwave absorber. J. Alloys Comp., 514, 183-188. 
10. Jimin, D. et al. (2005). Control of $\mathrm{ZnO}$ morphologies via surfactants assisted route in the subcritical water. J. Cryst. Growth, 280, 126-134.

11. Hull, D. \& Clyne, T. W. (2000). An introduction to composite material, 2nd ed. Cambridge: Cambridge University Press.

12. Li, Z. et al. (2003). Selected-control synthesis of zno nanowires and nanorods via a peg-assisted route. Inorg. Chem., 42, 8105-8109.

13. Song, J. H. et al. (2005). Systematic study on experiment condition for largescale growth of aligned $\mathrm{ZnO}$ nanowires on nitrides. J. Phys. Chem. B, 109, 9869-9872.

14. Lu, R. T. et al. (2010). High performance multiwall carbon nanotube. $J$. Appl. Phys., 108, 084305-084309.

15. Odom, T. W. et al. (2013). Atomic structure and electronic properties of single-walled carbon nanotubes. Nature, 391, 62-64.

16. Saville, P. Huber, T. \& Makeiff, D. (2005). Fabrication of organic radar absorbing materials. Technical Report. Canada: Defence Research and Development Canada Atlantic.

17. Mc Kelvey, J. P. (1986). Solid state and semiconductor physics. Florida: Robert E. Kriger Publishing Company. 